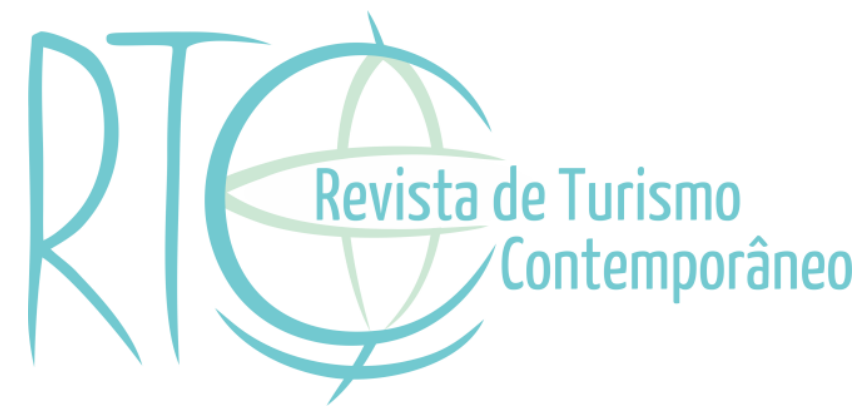

\title{
Políticas públicas de turismo na região de Serra Negra, Bezerros - Pernambuco: o estudo das ações governamentais de 2013 a 2018
}

Public tourism policies in the region of Serra Negra, Bezerros - Pernambuco: the study of government actions from 2013 to 2018

Alba de Oliveira Barbosa Lopes

Professora titular da área de Gestão e Negócios do Instituto Federal de Pernambuco - IFPE, Recife/PE, Brasil

E-mail: alba.barbosa@paulista.ifpe.edu.br

Maria Claudlena Barbosa da Silva

Especialista em Gestão Pública pelo Instituto Federal de Pernambuco - IFPE, Recife/PE, Brasil E-mail: cal_barsy@hotmail.com

Artigo recebido em: 16-03-2020

Artigo aprovado em: $19-10-2020$ 


\section{RESUMO}

O artigo tem como objetivo investigar ações governamentais desenvolvidas no distrito de Serra Negra, Pernambuco, voltadas para a atividade turística. Esta pesquisa qualitativa e descritiva está relacionada a ações governamentais no período de 2013 a 2018. A coleta de dados é baseada em documentos institucionais nos níveis nacional, estadual e municipal, além de entrevista semiestruturada com a gestora municipal de turismo. Observou-se que algumas ações foram concluídas e outras, que se concentram diretamente na preservação da região, ainda estão em fase de elaboração ou implementação. Algumas ações são desconhecidas da administração local, apesar de mencionadas em documentos do governo estadual. Serra Negra foi inserida em três Programas como objeto de políticas públicas: Prodetur Nacional de Pernambuco, Pernambuco para o Mundo e Regionalização do Turismo. As informações sobre a execução local do Programa Pernambuco para o Mundo e do Programa de Regionalização do Turismo não foram obtidas a partir da pesquisa documental, nem da entrevista, o que pode indicar que essas políticas públicas não foram realizadas. No caso do Prodetur Nacional de Pernambuco, o projeto de valorização turística da região foi parcialmente realizado. Há uma gestão desarticulada entre o poder local e a liderança das ações do poder estadual, por isso é necessário fortalecer a institucionalização municipal para que atuem mais ativamente nas decisões de turismo. Além de fortalecer a gestão local, é necessário ativar o Conselho Municipal para que os interesses dos atores privados, o terceiro setor e a comunidade local também possam ser incluídos na agenda pública do turismo.

Palavras-chave: Políticas públicas. Turismo. Planejamento. Serra Negra.

\section{ABSTRACT}

The article has the intention of investigating governmental actions developed in the district of Serra Negra, Pernambuco, focused on the tourist activity. This qualitative and descriptive research is related to governmental actions in the period from 2013 to 2018. Data collection is based on institutional documents at the national, state and municipal levels, as well as semistructured interview with the municipal tourism manager. It was observed that some actions have been concluded, and others, which focus directly on the preservation of the region, are still at the stage of elaboration or implementation. Some actions are unknown to the local management, despite being mentioned on state government documents. Serra Negra was inserted in three Programs as the object of public policies: Prodetur Nacional Pernambuco, Pernambuco para o Mundo, and Regionalização do Turismo. Information on the local execution of Pernambuco para o Mundo Program and Regionalização do Turismo Program was neither obtained from the documental research, nor in the interview, which may indicate that these public policies were not carried out. Regarding Prodetur National Pernambuco, the project of the tourist valorization of the region was partially accomplished. There is a disjointed management between local power and leadership of actions by the state power, so it is necessary to get the municipal institutionalization stronger so that they act more actively in tourism decisions. In addition to strengthening local management, it is necessary to activate the Municipal Council so that the private actors' interests, the third sector and the local community can also be included in the public agenda of tourism.

Keywords: Public Policies. Tourism. Planning. Serra Negra. 


\section{INTRODUÇÃO}

O Turismo é uma das atividades que tem influenciado positivamente a economia brasileira, movimentando cerca de US $\$ 56,8$ bilhões em 2016, equivalendo a 3,2\% do Produto Interno Bruto do Brasil. A atividade é uma grande geradora de empregos em diversas organizações como meios de hospedagem, agências de viagens, transportadoras, parques temáticos, restaurantes, etc. e criou, em 2016, 7 milhões de empregos nas atividades características do turismo (Brasil, 2018).

Nas últimas décadas, o turismo tem sido inserido na agenda política de diversos governos, sob o discurso que a atividade tem potencial para gerar emprego e renda para as localidades. Entidades internacionais importantes como a Organização para a Cooperação e Desenvolvimento Econômico (OCDE) e Organização das Nações Unidas (ONU), por meio da Organização Mundial do Turismo (OMT) apresentam o turismo como fator de desenvolvimento regional.

No Brasil, o setor foi marcado por uma presença mais forte dos entes governamentais na década de 1990 em ações de infraestrutura básica e turística, campanhas promocionais e capacitação da mão-de-obra. Avanços institucionais como a criação do Ministério do Turismo, em 2003; o lançamento da Política Nacional de Turismo, em 2008 e a formalização de Planos Nacionais, em 2002, 2007, 2013 e 2018 contribuíram para consolidação e a legitimação das ações desenvolvidas.

Apesar da inserção das atividades nas ações dos governos e dos números expressivos da atividade no país, o desenvolvimento de regiões por meio da atividade turística é uma questão controversa. O turismo ao mesmo tempo que proporciona benefícios à localidade como geração de divisas, aumento do número de empregos, valorização do patrimônio cultural e natural, também tem potencial para acarretar malefícios como: degradação do meio ambiente, ruptura de hábitos e costumes locais, conflitos com a comunidade, aumento dos preços dos produtos e das moradias, entre outros impactos decorrentes de um desenvolvimento desordenado (Arrones, 1992; Crick, 1992; Melo, 2005).

Com potencial para impulsionar ou limitar o desenvolvimento de regiões, aumenta a necessidade de intervenções governamentais no turismo. A Carta do Turismo e Código do Turista, publicada em 1985, pela OMT, apresentou detalhes sobre as responsabilidades dos governos, os quais devem:

integrar sua política turística a sua política global de desenvolvimento em seus diversos níveis - local, regional, nacional e internacional - e ampliar a cooperação 
turística em nível bilateral e multilateral, também no contexto da Organização Mundial do Turismo [...]; encorajar a adoção de medidas que permitam a participação de todos ao turismo nacional e internacional, especialmente pela organização do tempo de trabalho e lazer, melhoria do regime de férias pagas anuais e a divulgação de datas de férias, com uma atenção particular ao turismo de jovens, de pessoas idosas e de deficientes físicos, e proteger, no interesse das gerações presentes e futuras, o meio ambiente turístico (Organização Mundial do Turismo - OMT, 1985, p. 44, tradução nossa $\left.{ }^{1}\right)$.

Uma região que foi objeto de ações de fomento do turismo é o distrito de Serra Negra, no município de Bezerros, Pernambuco. Distante 117 quilômetros da capital do Estado, Serra Negra tem despontado como um dos principais destinos de ecoturismo e como polo de atrações no período de festas juninas na região (Divulgada programação, 2018; Markman, 2011; Rocha, 2016).

No âmbito nacional, Serra Negra esteve inserida no Mapa do Turismo, do Programa de Regionalização do Turismo, na categoria de Serras e Artes em todas as edições (2004, 2006, 2009, 2013, 2016, 2017 e 2018). No âmbito regional, inserido no Polo Agreste do Programa Regional de Desenvolvimento do Turismo (Prodetur) Nacional Pernambuco, parcialmente financiado pelo Banco Interamericano de Desenvolvimento (BID). No âmbito estadual, o distrito está inserido no Plano de Pernambuco para o Mundo, que é o plano estratégico do governo de Pernambuco com horizonte temporal de 2008 a 2020. A região de Serra Negra está inserida na região de desenvolvimento III, que é uma região composta por municípios com algum fluxo turístico, com potencial de crescimento, mas que não possuem um desenvolvimento organizado.

Tomando como referência, a relevância das intervenções governamentais no desenvolvimento do turismo e observando que a região de Serra Negra, em Bezerros, Pernambuco, vem sendo objeto de ações federais e estaduais, buscou-se investigar: Quais ações governamentais na área de turismo foram desenvolvidas em Serra Negra entre os anos de 2013 a 2018? Essa delimitação temporal compreende ao horizonte de atuação do penúltimo Plano Nacional de turismo e aos 5 últimos anos da coleta de dados.

As autoras compreendem que a ação pública é composta por atores diversos, sejam pertencentes ou não ao aparelho do Estado. Sabe-se, também, por meio dos estudos da análise cognitiva de políticas públicas, que o Estado não possui o monopólio da fabricação ou produção

\footnotetext{
${ }^{1}$ Do original: Intégrer leur politique touristique à leur politique globale de développement à ses divers niveauxlocal, régional, national et international - et élargir la coopération touristique aussi bien dans un cadre bilatéral que multilatéral, ainsi que dans le cadre de l'Organisation Mondiale du Tourisme, [...]; encourager l'adoption des mesures permettant la participation de tous au tourisme national et international, notadament par l'aménagement des temps de travail et de loirs, l'amélioration du régime des congés payés annuels et l'étalement des dates de congés, ainsi que par une attention particulière au tourisme des jeunes, des personnes âgées et des handicapés, et protéger, dans l'intérêt des génération présentes et à venir, l'environnement touristique.
} 
das políticas públicas uma vez que elas, conforme Lascoumes e Le Galès (2012), são elaboradas com uma multiplicidade de atores os quais projetam seus interesses e expectativas no processo, sendo, portanto, as políticas públicas o resultado das ações de atores importantes no jogo de mediações que trabalham para prevalecer seus interesses.

Apesar da crença que seria necessário, para uma análise mais profunda da ação pública no turismo em Serra Negra, a ampliação do estudo para as atuações de atores públicos, privados e do terceiro setor no turismo, esse estudo foca sua análise nas ações governamentais nos níveis federal, estadual e municipal, por considerar o Estado como um ator bastante relevante das ações de fomento ao turismo. O estudo de atores relevantes da iniciativa privada e terceiro setor fazem parte da agenda futura de pesquisas das autoras.

\section{REVISÃO DE LITERATURA}

O turismo é disseminado pela OMT como um "fenômeno econômico, social e cultural, que envolve o deslocamento de pessoas para países ou lugares fora do seu entorno para fins pessoais ou profissionais ou de negócios" (OMT, 2013, tradução nossa ${ }^{2}$ ), por um período inferior a um ano. Como pode ser notado na definição anterior, o turismo envolve a viagem, bem como a permanência fora do domicílio habitual. Para recepcionar os turistas na comunidade devem ser desenvolvidas, conforme Beni (2008), a infraestrutura básica a qual, é utilizada não exclusivamente por um setor e a infraestrutura turística, ou seja, aquela específica ao setor como equipamentos e serviços para o atendimento das necessidades dos turistas. Esses investimentos, sejam eles públicos ou privados, influenciarão o nível de competitividade dos destinos turísticos.

O turismo é um fenômeno fragmentado e particularmente extenso. Conforme exposto na metodologia de contas satélites ${ }^{3}$ proposto por Organização das Nações Unidas - ONU, Organização Mundial do Turismo - OMT e Organização para a Cooperação e Desenvolvimento Econômico - OECD (2008), ele se estende por um conjunto de atividades produtivas que podem atender as necessidades dos viajantes que envolvem serviços de hospedagem, alimentação e transporte dos visitantes; serviços de agências de viagens; serviços culturais, esportivos e de recreação; dentre outros.

\footnotetext{
${ }^{2}$ Do original: Le tourisme est un phénomène social, culturel et économique qui implique le déplacement de personnes vers des pays ou des endroits situés en dehors de leur environnement habituel à des fins personnelles ou professionnelles ou pour affaires.

${ }^{3}$ Conta Satélite é uma ferramenta de mensuração desenvolvida e disseminada pela OMT a seus membros como forma de padronizar e tornar mais eficaz a mensuração dos resultados da atividade na economia desses países.
} 
Voltando ao atendimento das necessidades dos consumidores turistas, percebem-se cada vez mais nas políticas governamentais segmentações da atividade com base na relação entre oferta e demanda, ou seja, para melhorar a adequação dos roteiros a ser oferecidos aos turistas com necessidades e expectativas específicas. Em Brasil (2006), são destacados doze segmentos e Beni (2008) apresenta pelo menos cinquenta e três abordagens de turismo praticadas no país. Este artigo não pretende destacar essas diferentes segmentações, mas abordar aquelas consideradas importantes para a análise turística em Serra Negra, a saber: ecoturismo; turismo de aventura e turismo cultural.

O ecoturismo possui implícito o uso sustentável dos atrativos turísticos ofertados aos visitantes, ou seja, existe uma preocupação em preservar o patrimônio, seja ele natural ou cultural e estimular seu uso de maneira consciente. De acordo com Brasil (2006, p. 9), esse turismo "caracteriza-se pelo contato com ambientes naturais e pela realização de atividades que possam proporcionar a vivência e o conhecimento da natureza, e pela proteção das áreas onde ocorre".

O turismo de aventura relaciona-se com o ecoturismo, contudo, ao longo das décadas se especializou tanto visando atender as necessidades dos turistas que adquiriu características mercadológicas próprias. Ele compreende "os movimentos turísticos decorrentes da prática de atividades de aventura de caráter recreativo e não competitivo" (Brasil, 2006, p. 39).

Os festejos juninos em Serra Negra, com a valorização, do forró e comidas típicas, caracterizam a representação de elementos culturais do povo nordestino. Conforme Brasil (2006), o turismo cultural compreende as atividades turísticas relacionadas à vivência do conjunto de elementos significativos do patrimônio histórico e cultural e dos eventos culturais, valorizando e promovendo os bens materiais e imateriais da cultura.

As segmentações da atividade voltadas ao atendimento do mercado turístico, acima descritas, são importantes para a análise, entretanto, no âmbito do artigo, o turismo é visto além dos aspectos econômicos tão ressaltados nas políticas públicas, pois também é um fenômeno social, político, cultural e ambiental de acordo com os entendimentos de Paiva (1995), Beni (2008) e ONU, OMT e OECD (2008). Quanto mais os governos focam suas ações apenas no desenvolvimento econômico, mais o fenômeno é reduzido à dimensão mercadológica.

O turismo, contudo, da mesma forma que pode contribuir para o progresso econômico, também pode maximizar as desigualdades sociais existentes na região e gerar externalidades ambientais que prejudicam o entorno. Para evitar tais aspectos negativos, as políticas públicas e o planejamento governamental deveriam estar atentos à multiplicidade de interesses dos atores envolvidos e aos impactos negativos para os níveis local, nacional e internacional. 
O turismo tem sido estimulado por meio do entendimento de que ele pode contribuir para o desenvolvimento de regiões, conforme apresentado anteriormente, entretanto, isto nem sempre se verifica. É possível uma localidade turística obter um desempenho satisfatório em índices econômicos, sem, contudo, avançar em indicadores sociais e ainda por cima, acentuar impactos ambientais negativos (Archer \& Cooper, 2002; Arrones, 1992; Crick, 1992).

\subsection{Políticas públicas de turismo}

Como exposto anteriormente, o turismo passou a ser objeto de políticas públicas em diversos governos. O termo "políticas públicas”, segundo Rua (2009, p. 17), “envolve mais do que uma decisão e requer diversas ações estratégicas selecionadas para implementar decisões tomadas". Não necessariamente precisa ser formalmente estabelecida por meio de um documento, como exposto em Dias (2003), uma vez que, para ele, a existência de ações no sentido de orientar, regulamentar ou coordenar o turismo caracteriza uma política. Contudo, as autoras deste artigo, optaram pela análise das ações governamentais formalmente estabelecidas e com área de atuação que englobasse a região de Serra Negra, como o Prodetur Nacional Pernambuco, o Programa Pernambuco para o Mundo e o Programa de Regionalização do Turismo.

Conforme Brasil (2015), os Programas Regionais de Desenvolvimento do Turismo (PRODETUR) podem ser solicitados por Estados da federação e o Distrito Federal e por capitais e municípios com mais de 1 milhão de habitantes. Eles buscam organizar as intervenções públicas para o desenvolvimento da atividade turística, através de prévios processos de planejamento das regiões turísticas. A partir desse planejamento, são propostas ações públicas nas áreas de produto turístico, promoção e comercialização, fortalecimento institucional, infraestrutura e serviços básicos e/ou gestão ambiental e social. Os investimentos do Prodetur são operacionalizados pelo Ministério do Turismo (MTur), que orienta tecnicamente as propostas estaduais e municipais; em parceria com organismos multilaterais, em especial o Banco Interamericano de Desenvolvimento (BID) e com a Corporação Andina de Fomento (CAF).

Conforme Brasil (2018), o Prodetur Nacional teve início em 2008 com contrato de empréstimos assinados pelos governos da Bahia, Ceará, Rio de Janeiro e Pernambuco e com recursos do Banco Interamericano de Desenvolvimento (BID) e Banco de Desenvolvimento da América Latina (CAF). Em Pernambuco, o Prodetur tem como objetivo "apoiar o desenvolvimento integrado do turismo sustentável através da melhoria da qualidade do produto 
turístico pernambucano e da estruturação dos Polos Costa dos Arrecifes, Agreste e Vale do São Francisco” (Brasil, 2018a). Serra Negra, distrito de Bezerros está inserido no Polo Agreste.

No plano estratégico de turismo estadual, Pernambuco para o Mundo, lançado em 2008, com horizonte temporal de 12 anos, foram analisadas as áreas turísticas e delimitadas as prioridades para o desenvolvimento do espaço. O objetivo foi priorizar os destinos com maior nível de estruturação e potencialidade da atividade turística, no curto prazo e, em seguida, outros destinos com potencial, mas ainda desestruturados. O plano visa: "transformar Pernambuco em destino turístico mais competitivo no mercado regional, nacional e internacional (...) e incorporar de modo permanente e reconceituado, atividades de diversos segmentos do turismo à tradicional atividade de sol e mar" (Pernambuco, 2008, p. 1). Bezerros encontra-se na área de desenvolvimento III, como pode ser visto no quadro 1, a seguir, os qual contempla destinos com potencial fluxo de turistas, mas sem organização adequada.

Quadro 1 - Municípios e níveis de desenvolvimento

\begin{tabular}{|c|l|c|}
\hline \multirow{2}{*}{ NÍVEIS } & \multicolumn{1}{|c|}{ POLOS E MUNICÍPIOS ABRANGIDOS } & $\begin{array}{c}\text { MUNICÍPIOS INDUTORES } \\
\text { DE DESENVOLVIMENTO }\end{array}$ \\
\hline \multirow{3}{*}{ I } & Fernando de Noronha: Fernando de Noronha & Fernando de Noronha \\
\cline { 2 - 3 } & Região Metropolitana: Recife, Olinda, Jaboatão dos Guararapes & Recife/Olinda \\
\cline { 2 - 3 } & Ipojuca: Ipojuca & Ipojuca \\
\hline \multirow{4}{*}{ II } & $\begin{array}{l}\text { Litoral Norte/Mata Norte: Goiana, Igarassu, Itamaracá, } \\
\text { Itapissuma, Paulista, Vicência, Nazaré da Mata, Carpina, } \\
\text { Tracunhaém, Paudalho, Lagoa do Carro. }\end{array}$ & Cabo de Santo Agostinho \\
\cline { 2 - 3 } & $\begin{array}{l}\text { Litoral Sul: Cabo de Santo Agostinho, Sirinhaém, Rio Formoso, } \\
\text { Tamandaré, São José da Coroa Grande, Barreiros. }\end{array}$ & Caruaru/Gravatá \\
\hline \multirow{4}{*}{ III } & $\begin{array}{l}\text { Agreste I: Caruaru, Gravatá, Garanhuns, Bezerros, Bonito, Brejo } \\
\text { da Madre de Deus }\end{array}$ & Petrolina \\
\cline { 2 - 3 } & Petrolina: Petrolina & Buíque \\
\hline \multirow{2}{*}{ IV } & \begin{tabular}{l} 
Agreste II: Buíque, Pesqueira, Arcoverde \\
\cline { 2 - 3 }
\end{tabular} & $\begin{array}{l}\text { Sertão I: Triunfo, Serra Talhada } \\
\text { Bom Conselho, Saloá, Belo Jardim, Poção, Taquarintiga do Norte, } \\
\text { Santa Cruz do Capibaribe, Toritama, Moreno, Camaragibe, } \\
\text { Quipapá, São Benedito do Sul, Palmares, Santa Maria da Boa } \\
\text { Vista; Lagoa Grande; São José do Egito; Afogados da Ingazeira; } \\
\text { São José do Belmonte; Santa Cruz da Baixa Verde; Salgadinho. }\end{array}$ \\
\hline
\end{tabular}

Fonte: Pernambuco, 2008, 10.

Os municípios do nível III, de acordo com o plano estratégico de turismo do Estado, são trabalhados no médio (2011 a 2015) e longo prazo (2016 a 2020), no qual as ações previstas eram, no primeiro período, capacitar a mão de obra empregada no turismo e os gestores do setor para atividade, desenvolver ações promocionais nos destinos e no segundo período, capacitar a gestão pública do turismo em âmbito municipal voltada a uma maior qualidade e continuidade das ações.

O Programa de Regionalização do Turismo foi criado em 2004 e tem como propósito a execução descentralizada e regionalizada com foco no planejamento coordenado e 
participativo, repercutindo positivamente nos resultados econômicos do território. São oito eixos de atuação: a gestão descentralizada do turismo; o planejamento e o posicionamento de mercado; a qualificação profissional dos serviços e da produção associada; o empreendedorismo, captação e promoção do investimento; a infraestrutura turística; a informação ao turista; promoção e apoio à comercialização e monitoramento (Brasil, 2013).

Um instrumento que auxiliar o desenvolvimento de políticas no âmbito do Programa de Regionalização é o Mapa do Turismo. Esse mapa é definido pelas Unidades Federadas pelos seus órgãos oficiais de turismo tendo como orientação os critérios mínimos estabelecidos pelo Ministério de Turismo.

Os municípios são separados em categorias de acordo com as peculiaridades e especificidades de cada região, para subsidiar a tomada de decisões. Bezerros, e consequentemente Serra Negra, está na região de Serra e Artes de Pernambuco, na categoria D. Conforme Brasil (2016) são 1.219 municípios nessa categoria representando locais nos quais a atividade turística encontra-se em estágio inicial.

Após apresentar os programas nos quais a região de Serra Negra está contemplada, e antes de seguir para a seção de apresentação dos procedimentos metodológicos, Brasil (2018) ressalta que esses planos e programas devem ser integrados e participativos. Dentre as instâncias de governança, o Conselho Municipal de Turismo é um ator importante na elaboração, implementação e avaliação das políticas públicas. De acordo com Brasil (2018b, p. 8), o conselho é "constituído por representantes da comunidade e tem como responsabilidade assessorar na definição e implementação de políticas públicas municipais". Ele contribui para o fortalecimento da gestão pública democrática e para a continuidade das ações no setor, mesmo com trocas de gestão.

\section{METODOLOGIA}

A pesquisa buscou analisar como a atividade turística tem sido desenvolvida no distrito de Serra Negra, Bezerros, Pernambuco pela atuação governamental, no horizonte de 2013 a 2018. Este estudo é qualitativo ao buscar compreender as ações governamentais no turismo na região. Conforme Silveira e Córdova (2009), esse tipo de pesquisa não se preocupa com representatividade numérica, buscando aprofundar a compreensão de um grupo social, de uma organização, etc. No caso deste artigo, o foco está nas ações governamentais, em âmbito federal, estadual e municipal, no turismo no distrito de Serra Negra. De acordo com o seu objetivo, este 
estudo é descritivo ao buscar descrever a atuação (e talvez, ausências) do Estado no desenvolvimento turístico da região.

Como fonte de coleta de dados este estudo alicerçou-se em documentos oficiais oriundos das esferas federal (documentos do Programa de Regionalização do Turismo e do Prodetur Nacional), estadual (Diários oficiais do Estado, site da Secretaria de Turismo e Empresa de Turismo de Pernambuco e documentos do programa Pernambuco para o mundo). Buscou-se, também, reportagens sobre o turismo no distrito nas bases de dados dos principais jornais do Estado (Jornal do Commercio e Diário de Pernambuco).

Apesar das tentativas com o governo municipal, não foram obtidos documentos físicos ou virtuais sobre a gestão do turismo local. Contudo, foi realizada uma entrevista com a Gerente de Turismo de Bezerros, por meio de um roteiro semiestruturado, abordando os seguintes temas: políticas públicas atuantes na região, forma de desenvolvimento e articulação das mesmas, desafios e problemas da região, etc. Os dados foram analisados com base na técnica de análise de conteúdo de Bardin (2011).

\section{RESULTADOS E DISCUSSÃO}

A seção está dividida da seguinte forma: primeiro foram expostas informações sobre a região no tocante aos aspectos geográficos, históricos e econômicos. Na segunda parte, abordou-se o turismo na região e as ações governamentais.

\subsection{Descrição da região}

Serra Negra está situada na região agreste de Pernambuco, distante $117 \mathrm{Km}$ da capital Recife. O distrito na área rural pertence ao município de Bezerros, o qual tem o principal acesso através da BR 232. Limita-se ao norte com os municípios de Cumaru e Passira; ao Sul com São Joaquim do Monte, Camocim de São Felix e Agrestina; ao Leste com Gravatá e Sairé; e a Oeste com Riacho das Almas e Caruaru, conforme apresentado na figura 1. 


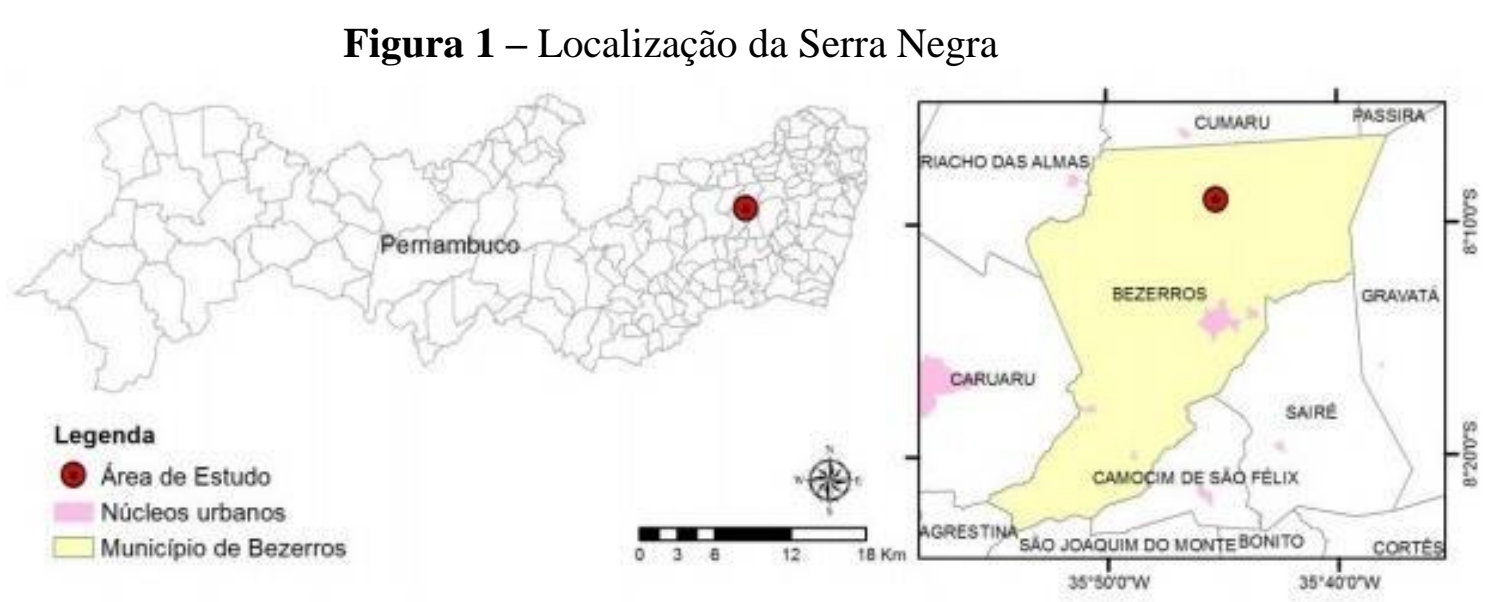

Fonte: Diaz, Soares, Ribeiro e Santos, 2017.

Tem altitude média de 800 metros, chegando a atingir 970 metros nas áreas mais elevadas, o que em função da altitude constitui um brejo de exposição possuindo temperatura mais amena, e um volume anual de chuva maior que o da área urbana de Bezerros. Encontrase assentado sobre a Província Borborema, onde podem ser encontradas as formações rochosas graníticas e inúmeras belezas naturais como mirantes e açudes. Sua flora é bastante diversa onde predomina a vegetação de mata serrana. Está situada na bacia hidrográfica do rio Capibaribe, próximo ao divisor de águas desta com o rio Ipojuca (Diaz, Soares, Ribeiro, \& Santos, 2017).

Segundo o Instituto Brasileiro de Geografia (Instituto Brasileiro de Geografia e Estatística - IBGE, 2019), em 2018, o município possuía uma população provável de 60.714 habitantes. As atividades econômicas de maior expressividade no município de Bezerros estão associadas ao setor terciário, concentrando $64,1 \%$ das pessoas ocupadas. Serra Negra é um dos locais mais visitados de Bezerros e está distante 10 quilômetros da cidade. Com uma população de 317 habitantes, possui 2 pousadas, 2 condomínios residenciais de luxo, 1 restaurante, um centro de artesanato e um anfiteatro, segundo dados de Pernambuco (2014). Entre os principais atrativos turísticos, naturais e culturais do distrito, destacam-se, conforme apresentado no quadro 2, a seguir: 
Quadro 2 - Atrativos turísticos da região de Serra Negra, Bezerros

\begin{tabular}{|l|l|}
\hline Polo Cultural & $\begin{array}{l}\text { Composto por: um anfiteatro com capacidade para 3.000 pessoas, onde é realizado } \\
\text { anualmente o São João da Serra. Com um mirante, um restaurante, posto de informações e } \\
\text { venda de artesanato local. }\end{array}$ \\
\hline Reserva natural & $\begin{array}{l}\text { Com uma área de } 6 \text { hectares, o Parque Ecológico da Serra Negra, é uma reserva de floresta } \\
\text { tropical, distante a } 3 \mathrm{~km} \text { do Polo Cultural. Nele podem ser observados os atrativos naturais: } \\
\text { a Porta do Vento, a Gruta do Amor, o Mirante do Gravatá Amarelo, o Pau Santo } \\
\text { Casamenteiro e o Mirante da Escada. }\end{array}$ \\
\hline $\begin{array}{l}\text { Sítio da Pedra } \\
\text { Solta }\end{array}$ & $\begin{array}{l}\text { Existe uma gigante pedra que parece realmente estar solta na natureza, situada em uma } \\
\text { propriedade particular o qual comporta uma pousada rústica. }\end{array}$ \\
\hline Caverna do Deda & $\begin{array}{l}\text { A gruta do Deda destaca-se por seu mirante localizado em um dos pontos mais altos de } \\
\text { Serra Negra. }\end{array}$ \\
\hline
\end{tabular}

Fonte: Baseado em Melo, 2005 e Pernambuco, 2014.

Além do exposto acima, Serra Negra possui mirantes, formações rochosas, grutas, flora remanescente da Mata Atlântica e Bioma da Caatinga. No local, existe estrutura para encontros culturais, camping, atividades de contemplação da natureza e esportivas. Conforme Pernambuco (2014), o local possui alto nível de atratividade turística devido aos aspectos paisagísticos singulares. Apesar disso, há exploração inadequada de recursos naturais, como especulação imobiliária e atividades agrícolas na área da Serra e problemas de circulação de veículos durante os festejos juninos. Então, conforme o documento, é preciso ordenar e qualificar a visitação para melhorar a mobilidade e o apoio ao desenvolvimento de atividades.

\subsection{Ações governamentais}

Conforme exposto na introdução, Serra Negra, é alvo de políticas, programas ou projetos em nível federal e estadual, de acordo com pesquisa documental preliminar. Inicialmente, pela análise documental, não foi possível identificar ações do governo municipal na região, salvo eventos promovidos pela prefeitura. As ações previstas na região no Prodetur Nacional Pernambuco estão expostas, a seguir, no quadro 3.

Quadro 3 - Ações inseridas no Prodetur Nacional Pernambuco

\begin{tabular}{|c|c|c|}
\hline \multicolumn{3}{|c|}{ PRODETUR NACIONAL PERNAMBUCO } \\
\hline AÇÃO & DESCRIÇÃO & STATUS \\
\hline $\begin{array}{l}\text { Ação } 1-\text { Projeto } \text { de } \\
\text { valorização turística da } \\
\text { Serra Negra }\end{array}$ & $\begin{array}{l}\text { Ampliação das condições de uso e atratividade turística da Serra } \\
\text { Negra }\end{array}$ & Incompleta \\
\hline $\begin{array}{l}\text { Ação } 2 \text { - Implantação de } \\
\text { lixeiras nas áreas de } \\
\text { interesse turístico }\end{array}$ & $\begin{array}{l}\text { Melhorar as condições de salubridade nos municípios do Polo, } \\
\text { investindo na coleta de resíduos sólidos, para que o aumento da } \\
\text { qualidade ambiental e de vida seja viabilizado }\end{array}$ & $\begin{array}{l}\text { Não foram } \\
\text { obtidas } \\
\text { informações }\end{array}$ \\
\hline $\begin{array}{l}\text { Ação } 3 \text { - Requalificação } \\
\text { do acesso à Serra Negra }\end{array}$ & $\begin{array}{l}\text { Requalificar as condições do acesso ao distrito por meio da } \\
\text { elaboração de estudo para adequação da mobilidade visando } \\
\text { melhorar a circulação na região }\end{array}$ & Concluída \\
\hline
\end{tabular}

Fonte: Pernambuco, 2014a.

O projeto de valorização da atividade turística (ação 1) está inserido no componente financiável Produto Turístico do Prodetur Nacional Pernambuco que tem como objetivos 
“investimentos relacionados com o planejamento, a recuperação e a valorização dos atrativos necessários para promover, consolidar ou melhorar a competitividade do destino em modalidade ou tipos específicos do turismo" (Pernambuco, 2016, p 4).

No caso de Serra Negra, três ações estavam previstas dentro do componente Produto Turístico: 1a) requalificação urbana, ordenamento e qualificação do ambiente para a realização de eventos; 1b) implementação e manejo de trilhas para realização de diferentes atividades turísticas e 1c) construção de um teleférico.

Sobre a requalificação urbana (ação 1a), foram noticiadas as seguintes notícias no Diário Oficial do Governo do Estado: licitação no 045/13 que trata da manifestação de interesse de empresa de consultoria para elaboração de estudo de viabilidade com vistas a implementação de projetos turísticos para valorização de atrativos localizados no polo agreste (Pernambuco, 2013) e licitação $n^{\circ}$ 002/16 que trata da contratação de serviços de consultoria especializada para elaboração de projeto executivo de requalificação urbana visando valorização turística do espaço cultural localizado nos altos da Serra Negra (Pernambuco, 2016a).

O Parque Ecológico da Serra Negra é uma Unidade de Conservação Municipal, tido como um dos principais pontos de visitação, o qual não apresentava medidas de controle para mitigar os efeitos negativos provocados pela atividade turística. Em 24 de março de 2017, o portal G1 de notícias, anunciou que o Parque Ecológico da Serra Negra seria sinalizado e que projeto vinha sendo planejado desde o ano anterior (Diaz, Soares, Ribeiro, \& Santos, 2017). Dando sequência sobre o atrativo, no dia 13 de julho de 2017, o Jornal Folha de Pernambuco anunciou que o Parque de Serra Negra receberia R \$ 2,3 milhões para mirante e escadarias, e esses recursos seriam para recuperação de trilhas e sinalizações, além da implantação de mirantes, escadarias, corrimões e a construção de um centro voltado para atividades de educação ambiental (Diaz, Soares, Ribeiro, \& Santos, 2017).

Conforme a gestora de turismo, o Plano de manejo do Parque Ecológico foi elaborado junto ao PRODETUR, dentro dele há os projetos específicos baseados em estudos prévios os quais foram encomendados propostas de implantação de infraestrutura, de sinalização e mobiliário para as trilhas e atrativos, o qual contém: o diagnóstico e a cartografia e seus respectivos atrativos composto pelos projetos executivos de paisagismo e arquitetura, além de projetos complementares, orçamento completo e a capacidade de carga/limite aceitável de visitação das estruturas projetadas; o projeto de sinalização, layouts das placas, orçamento detalhado, descrição de material. Segundo a Secretaria de turismo, o plano está pronto só não 
foram iniciadas as ações pelo PRODETUR por estarem aguardando o licenciamento ambiental, necessário para a atividade.

No documento acima, também está contido o caderno de intervenções para manejo das trilhas (ação 1b), o qual reunirá projetos executivos modelos padrão destinados ao provimento de infraestrutura física das trilhas do Parque. Além dessa ação, em 2015, houve o detalhamento dos elementos necessários para a execução da obra de implantação de uma trilha ciclística que envolvia Bezerros e outros municípios do Polo Agreste. Em Pernambuco (2015) consta que o projeto previa 182,60 quilômetros de trilha entre Gravatá, Serra Negra, Caruaru, Bonito e Sairé. A figura 2 apresenta os trechos da trilha. Serra Negra está entre os trechos 1 e 2.

Figura 2 - Trilha ciclística Agreste

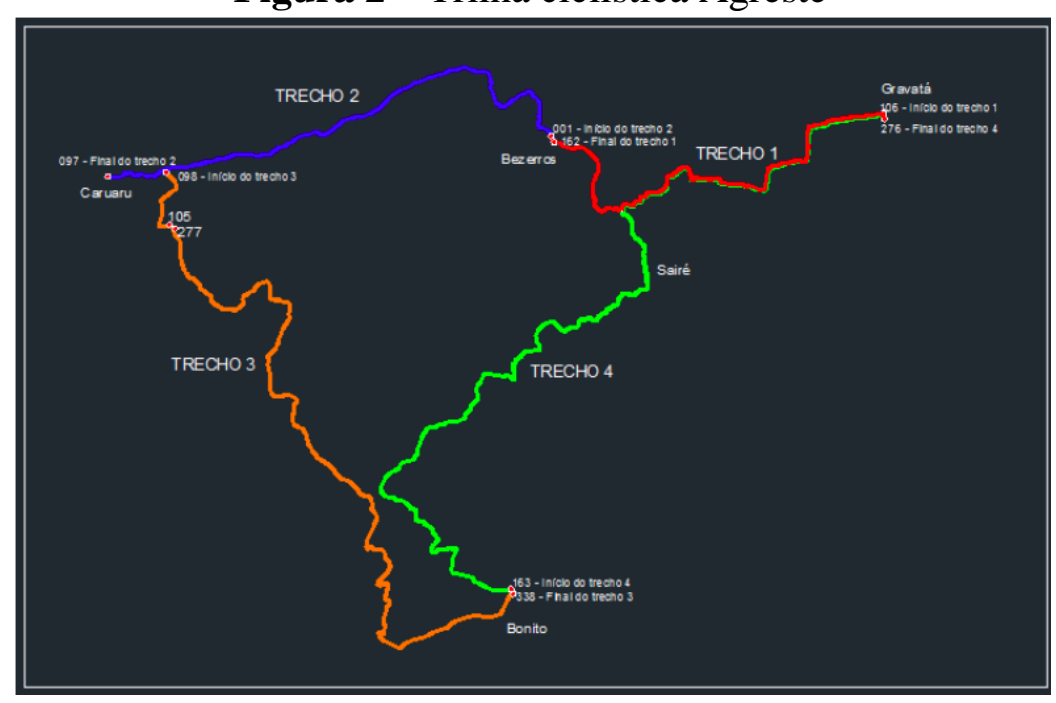

Fonte: Pernambuco, 2015, p. 3.

A sinalização existente foi feita dentro do PRODETUR, contudo, a gestora de turismo declarou desconhecer a implementação do roteiro justificando que algumas ações do PRODETUR não são repassadas para eles.

A discussão sobre o teleférico (ação 1c) foi noticiada em instrumentos públicos e privados, como a notícia da contratação de empresa para construção, aquisição e instalação de teleférico em Serra Negra pelo Diário Oficial do Estado, em 2013 - processo licitatório 27/2013 (Pernambuco, 2013a).

Embora tenha-se feito o estudo de viabilização e a aquisição dos terrenos onde seriam instaladas as bases do teleférico, tanto que entraram com o processo licitatório, o programa existente na época que financiava a construção acabou, conforme a gestora de turismo, não chegando a ser implementado. Segundo a entrevistada: 
(sic) tudo ok. Quando foi o ano passado ou foi no ano retrasado num (sic) recordo bem. Aí alegaram que não tinha viabilidade, não entendi o porquê, porque desde o início quando as equipes vieram pra (sic) cá (sic) fazer o levantamento, eles sempre mostravam que existia viabilidade. É tanto que entraram com processo licitatório, né? (sic). E depois a justificativa deles pra (sic) gente é que não tinha viabilidade, por isso não foi feito. Aí fica aquele jogo político dizendo que vai ser feito coisa e tal, mas o programa... o PRODETUR que existia na época pra (sic) financiar ele, ele já acabou, o programa então não tem mais como...O PRODETUR daquele período não tem mais como.

O projeto de implantação de lixeiras na área (ação 2) está inserido no componente Infraestrutura e Serviços Básicos, o qual "integra investimentos em infraestrutura e de serviços não vinculados diretamente a produtos turísticos, mas necessários para gerar acessibilidade ao destino e dentro dele e satisfazer as necessidades básicas do turista" (Pernambuco, 2016, p. 6). A implantação das lixeiras que permitam a separação de resíduos foi projetada a partir do mapeamento das lixeiras existentes e definição das substituições necessárias, nos atrativos e no entorno, além da definição de pontos que deverão ser implantadas as 20 lixeiras ao longo da Serra.

Apesar de constar em Pernambuco (2016), quando questionada, a gestora não soube informar se chegaram a ser instaladas, ou se foram instaladas através de outra secretaria. A mesma, no momento da entrevista, perguntou a outros participantes da secretaria que estavam a mais tempo que ela. Esse desconhecimento das ações é preocupante, pois pode indicar uma desarticulação entre o órgão executante do Prodetur e a gestão pública municipal. Aliado a isso, o enfraquecimento da gestão local também é indicado pela não atuação do Conselho Municipal de Turismo. Conforme a gestora, o conselho, criado em 1999, não está ativo;

$\mathrm{Na}$ realidade o conselho quando foi criado, só teve um presidente, ai (sic) foi esquecido. Ai (sic) a gente tá (sic) retornando ele, (pois) é uma exigência do ministério do Turismo, a gente ter os conselhos para poder participar da região turística. Ele tinha sido enviado pra (sic) câmara pra (sic) poder atualizar os seguimentos (pois) muita coisa tinha mudado de lá pra (sic) cá. Só que houve uma mudança no organograma da prefeitura. Então a nossa Secretaria de Desenvolvimento Econômico e Turismo, que hoje ela é Turismo e Cultura, vai ter que refazer novamente pra (sic) poder convocar os membros e colocar o conselho pra (sic) frente.

Essa questão é importante, pois a falta do conselho e de uma gestão municipal mais atuante na elaboração, implementação e avaliação de políticas pode distanciar as ações executadas dos interesses da comunidade local. Para Brasil (2018b, p. 8), o conselho é:

o primeiro passo para se pensar no desenvolvimento integrado das ações que visam consolidar a atividade turística como atividade econômica importante ajudando na valorização cultural, social e da preservação ambiental, que possibilite turistas e moradores o maior contato com sua história, seus patrimônios e riqueza cultural e natural. 
A ação de requalificação do acesso (ação 3), inserida também no componente Infraestrutura e Serviços Básicos, teve como objetivo requalificar os 10 quilômetros de acesso à Serra Negra com vista a melhorar a circulação a região. A obra foi concluída em 2015 e, conforme Pernambuco (2015a), um trecho de 8,57 quilômetros foi pavimentado e 1,3 recuperado ao custo de 10,3 milhões de reais. A pavimentação foi concluída melhorando o fluxo principalmente na época de mais movimento, durante os festejos juninos.

As ações previstas no Programa Pernambuco para o Mundo para a região III, onde Serra Negra está inserida estão sintetizadas no quadro 4, a seguir. São três ações voltadas à implementação da infraestrutura, ao fortalecimento institucional e à estruturação do produto turístico. O referido programa não informa quais atividades estão previstas exatamente nessas ações definidas.

Quadro 4 - Ações inseridas no Programa Pernambuco para o Mundo

\begin{tabular}{|l|l|l|}
\hline \multicolumn{2}{|c|}{ AÇÃO } & \multicolumn{1}{|c|}{ PERNAMBUCO PARA O MUNDO } \\
\hline \multicolumn{1}{|c|}{ DESCRIÇÃO } & \multicolumn{1}{c|}{ STATUS } \\
\hline $\begin{array}{l}\text { Ação 1 - Implementação da } \\
\text { Infraestrutura básica }\end{array}$ & Investimentos públicos em saneamento na região & $\begin{array}{l}\text { Não foram obtidas } \\
\text { informações }\end{array}$ \\
\hline $\begin{array}{l}\text { Ação 2 - Programa de } \\
\text { fortalecimento institucional }\end{array}$ & $\begin{array}{l}\text { Implantação de programa para tornar a gestão pública } \\
\text { municipal mais eficaz }\end{array}$ & $\begin{array}{l}\text { Não foram obtidas } \\
\text { informações }\end{array}$ \\
\hline $\begin{array}{l}\text { Ação 3 - Estruturação do } \\
\text { produto turístico }\end{array}$ & $\begin{array}{l}\text { Estruturação de produtos e comercialização ao } \\
\text { público regional }\end{array}$ & $\begin{array}{l}\text { Não foram obtidas } \\
\text { informações }\end{array}$ \\
\hline
\end{tabular}

Fonte: Pernambuco, 2008.

Como não foram obtidas informações sobre as ações do governo estadual do Programa Pernambuco para o Mundo executadas em Serra Negra na pesquisa documental, seja nos diários oficiais, relatórios de gestão da secretaria de turismo, nem nos jornais do Estado, nem com a entrevista com a gestora de turismo, foram solicitadas informações na Gerência de Produtos e Destinos Turísticos da Empresa de Turismo de Pernambuco (EMPETUR), contudo, essas não foram cedidas no tempo de coleta de dados (abril e maio/2019 e setembro e outubro/2019). A ausência, todavia, de informações na fase documental e na fase de entrevista com a gestora, já pode ser considerada um indicador de dificuldades na execução das ações.

Em relação à ação 1, contudo, no início de 2019, foi noticiado que a Companhia Pernambucana de Saneamento (COMPESA) estava em fase de elaboração dos Planos Regionais de Saneamento Básico das Bacias Hidrográficas dos Rios Ipojuca e Capibaribe, onde Bezerros está inserida, para ser implementados nos próximos 20 anos. Com esses planos regionais, os municípios, conforme Planos regionais (2019), poderão elaborar seus planos municipais de saneamento. 
Sobre o Programa de Regionalização do Turismo, não foram obtidas informações de quais ações estavam sendo desenvolvidas na localidade. Sabe-se que o programa atua em oito eixos, conforme explicado no referencial teórico da pesquisa (a gestão descentralizada do turismo; o planejamento e o posicionamento de mercado; a qualificação profissional dos serviços e da produção associada; o empreendedorismo, captação e promoção do investimento; a infraestrutura turística; a informação ao turista; promoção e apoio à comercialização e monitoramento), contudo, as informações sobre ações na região de Serra Negra não estavam acessíveis nem pela pesquisa documental, nem com a gestora de turismo do município.

\section{CONSIDERAÇÕES FINAIS}

Este artigo teve a pretensão de identificar quais ações governamentais foram desenvolvidas no Distrito de Serra Negra no período de 2013 a 2018. Serra Negra é objeto de ações declaradas em três frentes: Prodetur Nacional Pernambuco, Programa Pernambuco para o Mundo e o Programa de Regionalização do Turismo. Observou-se que algumas ações foram concluídas e outras, que focam diretamente na preservação da região, ainda estão em fase de elaboração ou execução, outras são desconhecidas pela gestão local, apesar de estarem citadas em documentos do governo do Estado.

No Prodetur Nacional Pernambuco, o projeto de valorização turística da região foi parcialmente realizado. Os projetos executivos, após avaliação de consultoria especializada, foram entregues, contudo ainda não foram implementados, aguardando o licenciamento ambiental. Trilhas ecológicas foram planejadas, mas não foram implementadas e o teleférico, divulgado inclusive na mídia, não será implementado por divergências em relação à viabilidade do projeto. A implantação de lixeiras nas áreas de interesse turístico não é de conhecimento da gestora. A ação concluída foi a requalificação do acesso à Serra Negra, obra importante que proporcionou segurança e rapidez no trajeto de 10 quilômetros entre Bezerros e Serra Negra.

No Programa Pernambuco para o Mundo estavam previstas ações de investimentos em saneamento na região, fortalecimento institucional e estruturação do produto turístico. Os investimentos em saneamento ainda não foram realizados e não foram obtidas informações acerca das outras ações. Da mesma forma, com as ações do Programa de Regionalização do Turismo. Não se pode afirmar que as ações não foram implementadas, contudo, a falta de informações publicadas, seja nos diários oficiais do Estado, na mídia, e o desconhecimento da gestora local de turismo, indica a não execução das ações. 
Observa-se uma gestão desarticulada do poder local e uma liderança de ações pelo poder estadual, sendo necessário um fortalecimento institucional no âmbito municipal para que eles atuem de forma mais ativa nas decisões do turismo. Além do fortalecimento da gestão local, se faz necessário ativar o Conselho Municipal para que os interesses dos atores privados, do terceiro setor e comunidade local também sejam inseridos na agenda pública de turismo.

\section{REFERÊNCIAS}

Archer, B., \& Cooper, C. (2002). Os impactos positivos e negativos do turismo. In Theobald, W. F. (Org.). Turismo global. São Paulo: Editora SENAC.

Arrones, F. J. (1992). Los mitos del turismo. In Arrones, F. J. Los mitos del turismo. Madrid: Endymion.

Bardin, L. (2011). Análise de conteúdo. Lisboa: Edições 70.

Beni, M. C. (2008). Análise estrutural do turismo. São Paulo: Editora SENAC.

Brasil. Ministério do Turismo. (2006). Segmentação do turismo: marcos conceituais. Brasília, DF. Recuperado em 23, maio, 2013, de

http://www.turismo.gov.br/export/sites/default/turismo/o_ministerio/publicacoes/downloads_ publicacoes/Marcos_Conceituais.pdf

Brasil. Ministério do Turismo. (2013). Programa de regionalização do turismo: diretrizes. Brasília, DF. Recuperado em 29, janeiro, 2019, de http://www.turismo.gov.br/images/programas_acoes_home/PROGRAMA_DE_REGIONALI ZACAO_DO_TURISMO_-_DIRETRIZES.pdf

Brasil. Ministério do Turismo. (2015). Prodetur. Recuperado em 20, janeiro, 2019, de http://www.turismo.gov.br/programas/5066-prodetur.html

Brasil. Ministério do Turismo. (2016). Categorização dos municípios das regiões turísticas doo mapa do turismo brasileiro. Recuperado em 20, janeiro, 2019, de http://mapa.turismo.gov.br/mapa/downloads/pdf/categorizacao/Cartilha_da_Categorizacao.pd $\mathrm{f}$

Brasil. Ministério do Turismo. (2018). Plano Nacional do Turismo 2018-2022: mais emprego e renda para o Brasil. Brasília, DF. Recuperado em 27, maio, 2018, de http://www.turismo.gov.br/images/mtur-pnt-web2.pdf

Brasil. Ministério do Turismo. (2018a). Pernambuco colhe resultados do investimento de $R \$$ 450 milhões por programa do MTur. Brasília, DF. Recuperado em 10, abril, 2018, de http://www.turismo.gov.br/\%C3\%BAltimas-not\%C3\%ADcias/12062-dez-anos-depois,pernambuco-colhe-resultados-de-investimento-de-r\$-450-milh\%C3\%B5es-viabilizados-porprograma-de-cr\%C3\%A9dito-do-mtur.html

Brasil. Ministério do Turismo. (2018b). Orientações técnicas para a criação do Conselho Municipal de Turismo. Brasília, DF. Recuperado em 05, outubro, 2019, de 
http://regionalizacao.turismo.gov.br/images/conteudo/CARTILHA_CONSELHOS_MUNICI PAIS_REVISADA_05_10_18.pdf

Crick, M. (1992). Representaciones del turismo internacional en las ciências sociales: sol, sexo, paisajes, ahorros y servilismos. In Arrones, F. J. Los mitos del turismo. Madrid: Endymion.

Dias, R. (2003). Planejamento do turismo: atualizado com o Plano Nacional de Turismo (2003/2007) de 29-4-2003. São Paulo, Atlas.

Diaz, C. C. F., Soares, D. B., Ribeiro, A. S., \& Santos, P, F, C. (2017). Diagnóstico ambiental do Parque Ecológico da Serra Negra, Bezerros-PE. In Congresso Brasileiro de Geografia Física, I., Campinas. Anais... Os Desafios da Geografia Física na Fronteira do Conhecimento. Campinas: Fapesp.

Divulgada programação do São João 2018 da Serra Negra, em Bezerros. (2018). Globo Nordeste. Recuperado em 13, janeiro, 2019, de https://g1.globo.com/pe/caruaru-regiao/saojoao/2018/noticia/divulgada-programacao-do-sao-joao-da-serra-negra-2018-embezerros.ghtml

Instituto Brasileiro de Geografia e Estatística - IBGE. (2019). Recuperado em 20, fevereiro, 2019, https://cidades.ibge.gov.br/brasil/pe/bezerros/panorama

Lascoumes, P., \& Le Galès, P. (2012). Sociologie de l'action publique: domaines et approches. Paris: Armand Colin.

Markman, L. (2011). Turismo de aventura esquenta clima ameno de Serra Negra, em PE. Globo Nordeste. Recuperado em 13, janeiro, 2019, de http://g1.globo.com/pernambuco/noticia/2011/12/turismo-de-aventura-esquenta-clima-amenode-serra-negra-em-pe.html

Melo, M. J. G. (2005). A Inserção do Ecoturismo no Brejo de Serra Negra/ Bezerros/ PE: uma proposta concreta de desenvolvimento socioespacial? $125 \mathrm{f}$. Dissertação de Mestrado do Curso de Geografia, Universidade Federal de Pernambuco, Recife, Pernambuco, Brasil.

Organisation Mondiale du Tourisme - OMT. (1985). Resolutions adoptées par l'assemblée générale a sa sixième session. Sofia, Bulgarie. Retrieved november, 06, 2011, from http://www.unwto.org/conferences/ga/det.php?id=158\&lang=F

Organisation Mondiale du Tourisme - OMT. (2013). Comprende le tourisme: glossaire de base. Retrieved may, 01, 2013, from http://media.unwto.org/fr/content/comprende-letourisme-glossaire-de-base

Organización das Naciones Unidas - ONU, Organizacíon Mundial del turismo - OMT, \& Organizacíon de Cooperación y Desarrollo Económicos - OCDE. (2008). Cuenta satélite del turismo: recomendaciones sobre el marco conceptual. Estudios de métodos, (80).

Paiva, M. G. M. V. (1995). Sociologia do turismo. Campinas, SP: Papirus.

Pernambuco. Secretaria de Turismo do Estado. (2008). Pernambuco para o Mundo: Plano Estratégico de Turismo de Pernambuco. São Paulo. Recuperado em 21, julho, 2018, de 
http://www2.setur.pe.gov.br/c/document_library/get_file?p_1_id=22093\&folderId=30717\&na me=DLFE-1984.pdf

Pernambuco. (2013). Manifestação de interesse, empresa de consultoria para elaboração de estudo de viabilidade com vistas a implementação de projetos turísticos para valorização de atrativos localizados no polo Agreste. Diário Oficial [do] Estado de Pernambuco, Poder Executivo. Recife, PE. Recuperado em 20, julho, 2018, de http://200.238.101.22/docreader/DocReader.aspx?bib=2013\&pesq=serra\%20negra

Pernambuco. (2013a). Contratação de empresa para construção, aquisição e instalação de teleférico em Serra Negra no município de Bezerros. Diário Oficial [do] Estado de Pernambuco, Poder Executivo. Recife, PE. Recuperado em 20, julho, 2018, de http://200.238.101.22/docreader/2013/9575

Pernambuco. Secretaria de Turismo. (2014). Estudo indicativo de capacidade de carga e seus indicativos de sustentabilidade de atrativos naturais do Polo Agreste. Olinda. Recuperado em 20, março, 2019, de

http://www.portais.pe.gov.br/c/document_library/get_file?p_l_id=24303939\&folderId=25367 $150 \&$ name $=$ DLFE-119215.pdf

Pernambuco. Secretaria de Turismo. (2014a). Plano de desenvolvimento integrado do turismo sustentável no Estado de Pernambuco - PDITS Polo Agreste. Recife. Recuperado em 10, abril, 2019, de

http://www.setur.pe.gov.br/c/document_library/get_file?p_l_id=24303939\&folderId=253941 95\&name=DLFE-119445.pdf

Pernambuco. Secretaria de turismo. (2015). Projeto de sinalização para cicloturismo nos municípios do Polo Agreste. Olinda, dez. 2015.

Pernambuco. (2015a). Governo reforça infraestrutura, turismo e sustentabilidade hidríca. Diário Oficial [do] Estado de Pernambuco, Poder Executivo. Recife, PE. Recuperado em 20, julho, 2018, de http://200.238.101.22/docreader/2015/1465

Pernambuco. (2016). Contratação de serviços de consultoria especializada para elaboração de projeto executivo de requalificação urbana visando valorização turística do espaço cultural localizado nos altos da Serra Negra - Programa Nacional de Desenvolvimento do Turismo Prodetur Nacional Pernambuco. Diário Oficial [do] Estado de Pernambuco, Poder Executivo. Recife, PE. Recuperado em 20, julho, 2018, de http://200.238.101.22/docreader/DocReader.aspx?bib=2013\&pesq=serra\%20negra

Pernambuco. Secretaria de Turismo. (2016a). Manual de operações Prodetur Nacional Pernambuco. Recife. Recuperado em 10, abril, 2019, de http://www.portais.pe.gov.br/c/document_library/get_file?p_l_id=24303939\&folderId=31605 $108 \&$ name $=$ DLFE-152510.pdf

Planos regionais de saneamento são apresentados em evento da AMUPE. (2019). Diário de Pernambuco. Estudos. Recife, 14 fev. 2019. Recuperado em 20, abril, 2019, de https://www.diariodepernambuco.com.br/app/noticia/vidaurbana/2019/02/14/interna_vidaurbana,777539/planos-regionais-de-saneamento-saoapresentados-em-evento-na-amupe.shtml 
Rocha, R. (2016). Com natureza e cultura, Pernambuco se diversifica da capital ao agreste. $O$ Globo. Recuperado em 13, janeiro, 2019, de https://oglobo.globo.com/boa-viagem/comnatureza-cultura-pernambuco-se-diversifica-da-capital-ao-agreste-19242842

Rua, M. G. (2009). Políticas Públicas. Florianópolis: Departamento de Ciências da Administração/ UFSC. Brasília: CAPES/ UAB.

Silveira, D. T., \& Córdova, F. P. (2009). A pesquisa científica. In Gerhardt, T. E., \& Silveira, D. T. Métodos de pesquisa. Coordenado pela Universidade Aberta do Brasil - UAB/UFRGS e pelo Curso de Graduação Tecnológica - Planejamento e Gestão para o Desenvolvimento Rural da SEAD/UFRGS. Porto Alegre: Editora da UFRGS.

FORMATO PARA CITAÇÃO DESTE ARTIGO

LOPES, A. O. B., \& SILVA, M. C. B. (2021). Políticas públicas de turismo na região de Serra Negra, Bezerros - Pernambuco: o estudo das ações governamentais de 2013 a 2018. Revista de Turismo Contemporâneo, 9(1), 83-103.

https://doi.org/10.21680/2357-8211.2021v9n1ID20110 